\title{
Bündnis gegen Depression?
}

\author{
M. und E. Aebischer-Crettol
}

Was die Gotland-Studie vor Jahren in eindrücklicher Weise aufzuzeigen vermochte, hat sich nun erneut schon in der ersten Phase des «Nürnberger Bündnisses gegen Depression» bestätigt: Die adäquate Behandlung von Depressionen kann die Suizidrate stark senken.

Während mehrerer Jahre haben wir übers Internet Menschen begleitet, die sich eigentlich mit einem Mail von dieser Welt verabschieden wollten. Indem wir uns auf ihre Not einliessen, konnten wir sie in der Regel dazu bringen, abgebrochene Therapien wieder aufzunehmen oder eine medikamentöse Therapie zu beginnen.

Leider hat es sich bis zuletzt immer wieder herausgestellt, dass Ärzte, die auf unser Drängen hin konsultiert wurden, die Patienten oder Patientinnen als nicht behandlungsbedürftig einschätzten oder ihnen Medikamente vorenthielten. Dabei war übers Internet diesen Konsultationen eines Arztes ein langer «Kampf» vorausgegangen. Es war mitunter äusserst schwer gewesen, die Skepsis, ja die Abneigung gegenüber einer medikamentösen Therapie zu überwinden und durch Beispiele zu entkräften.

Die Frustration der Hilfesuchenden nach mitunter unverständlich schroffer Verweigerung ärztlicher Hilfeleistung und auch unsere Enttäuschung darüber war dann jeweils sehr gross. Die Anstrengung, wieder Vertrauen in fachärztliche Behandlung zu gewinnen, war noch grösser.

Wir möchten hier das Beispiel einer 18jährigen Frau schildern, die sich am 18. Mai 2002 per Internet das erste Mal an uns wandte:

«Ich will mich sterben lassen. Niemand mag mich. Wenn ich mir die Venen aufschneide, graut mir vor dem Blutbad und wenn ich eine Schachtel Schlafmittel nehme, habe ich Angst, dass das nicht genügt. Ich wollte mich schon erhängen, aber der Knoten misslang mir. Auch tut mir der leid, der mich so findet. [...] Ich weiss, dass ich Unglück bringe [...].»

Am 24. November 2002 schrieben wir, nachdem in der Zwischenzeit über 70 Mails von bis zu drei A4-Seiten ausgetauscht worden waren:

«Die Idee zu sterben beschäftigt dich nach wie vor. [...] Es ist unabdingbar, dass du dich wegen des grundlegenden Problems, unter dem du leidest, behandeln lässt: der Depression. Hier liegt die Lösung deiner Probleme und nicht im Tod. [...] Suche einen guten Arzt und erzähle ihm ALLES: Dass du keine
Kraft mehr hast, dass du dich elend fühlst, dass du nichts mehr essen magst, dass du immerzu weinen musst und dass du nur eine fixe Idee hast, nämlich zu sterben! Bitte deinen Arzt, dir zu helfen, dir ein geeignetes Antidepressivum zu verschreiben und alles zu unternehmen, was seiner Meinung nach wichtig für deine Genesung ist.»

Am 25. November 2002 schrieb die Frau zurück: «Nun gut, ich werde die zwei Schachteln probieren, die mir der Arzt mitgegeben hat. [...] Ich hab zwar keine grosse Lust. [...] Es gibt Leute, die haben nie Probleme. Bei mir geht immer alles schief.»

\section{Am 27. Dezember 2002 schrieben wir ihr:}

«Auf jeden Fall nimm unbedingt das Cipralex weiter. Aus deiner Art zu schreiben merke ich, dass es schon eine gewisse Wirkung gezeigt hat und es ist zu erwarten, dass es dir bald besser geht. Aber es braucht ein wenig Geduld. Der Weg aus einer Krise ist immer ein Weg und niemals ein Sprung.»

Gleichentags schrieb sie zurück:

«Der Arzt sagte mir, wegen dem, was mir da passiert sei, mache man keine Depression. Er gäbe mir noch für einen Monat Tabletten und dann fertig. [...] Auch er hält mich also für einen Idioten.»

Am 29. Dezember 2002 schrieb sie weiter:

«Ja, ich glaube schon, dass es mir besser geht. [...] Ich habe das Gefühl, dass ich in der Tat wieder werde wie früher.»

Und am 30. Dezember 2002:

«Was die Medikamente betrifft habe ich den nächsten Arzttermin am 2. Februar. Das Problem ist nur, dass mir die Tabletten nur bis zum 27. Januar reichen. Ich weiss nun nicht, was ich machen soll. Ich werde den Arzttermin absagen. Er hat mir ja sowieso gesagt, dass er mit der Behandlung aufhört, sobald es mir besser geht.»

Leider steht dieses Beispiel nicht allein. Wenn aber weiterhin einzelne Ärzte so mit Patientinnen umgehen, dann sind alle Bemühungen zur Bekämpfung von Depressionen und damit eine wirksame Suizidprävention umsonst.
Dr. theol. Monique Aebischer-Crettol, Pfr. Dr. Ebo Aebischer-Crettol Waldriedstrasse 23 CH-3074 Muri b. Bern 